University of Rhode Island

DigitalCommons@URI

Open Access Master's Theses

1933

\title{
Some Effects of Pressure Upon the Embryological Development of The Domestic Fowl (Gallus Domesticus)
}

Harry Fisher Amadon

University of Rhode Island

Follow this and additional works at: https://digitalcommons.uri.edu/theses

\section{Recommended Citation}

Amadon, Harry Fisher, "Some Effects of Pressure Upon the Embryological Development of The Domestic Fowl (Gallus Domesticus)" (1933). Open Access Master's Theses. Paper 1143.

https://digitalcommons.uri.edu/theses/1143

This Thesis is brought to you for free and open access by DigitalCommons@URI. It has been accepted for inclusion in Open Access Master's Theses by an authorized administrator of DigitalCommons@URI. For more information, please contact digitalcommons-group@uri.edu. 
591.3

Ami2

SONE EFFECTS OF PRESSURE

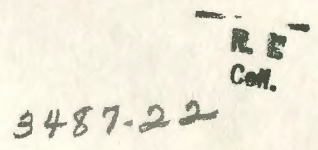

UPON

THE EMBRYOLOGICAL DEVELOPNENT

$\underline{O F}$

THE DOMESTIC FOWL

(GALIUS DONESTICUS)

$\underline{B Y}$

HARRY PISHER AMADON

A THESIS SUBMITTED IN PARTIAL FULFILLNENT OF THE REQUIREMENTS FOR THE DEGREE OF

MASTER OF SCIENCE

. IN

ZOOLOGY

RHODE ISLAND STATE COLLEGE 


\title{
MASTER OF SCIENCE THESIS
}

\author{
$\mathrm{OF}$
}

HARRY FISHER AMADON

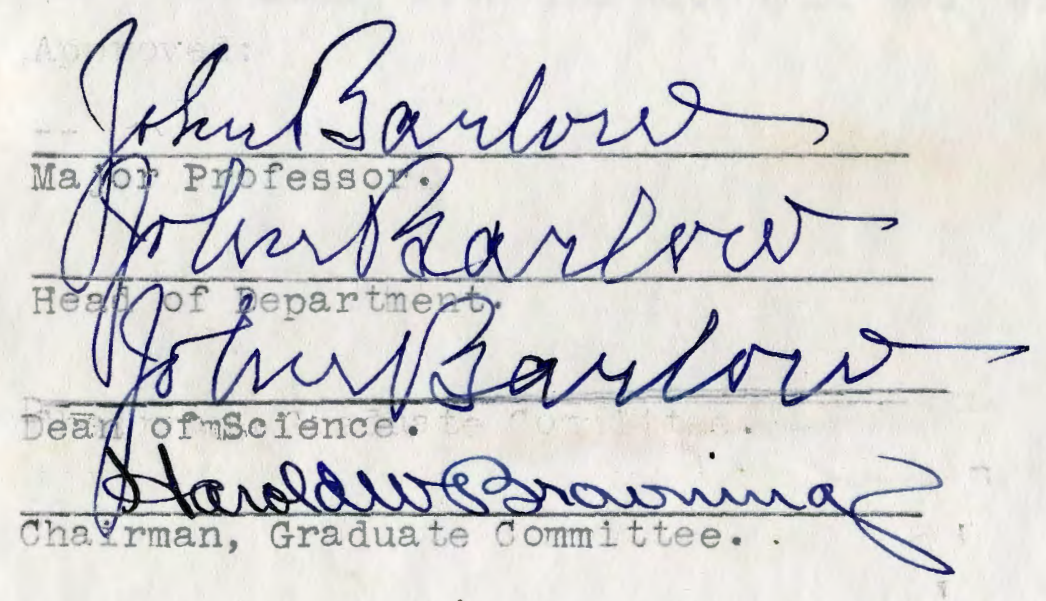

RHODE ISTAND STATE COLIEGE

1933 


\section{ABSTRACT}

In an investigation of the effect of pressure on the developing chick embryo, all environmental factors excepting varying degrees of compression were kept constant.

Eggs were sealed in a compression chamber fitted with a thermometer for temperature control.

A lethal pressure was determined somewhat above sixty pounds. Pressures near this point caused gross malformations including an anamiotic condition.

the general effect of pressure is acceleration of structure formation along with diminution of body size. 


\section{INTRODUCTION}

The writer's first interest in pressure as a factor in the environment ofanimal life was aroused several years ago when he came upon one of Pflüger's early accounts (1884) of the effect of compressing amphibian eggs between two plates of glass. Until that time he had given but little attention to any of the vital relationships between the growing embryo and its internal and external physical conditions. His conception of the cleavage of the fertilized egg as the differentiation of the potential adult had been essentially that held by most embryologists of the present time. Those chemical and mechanical complications of cell division which substantiated the chromosome theory he accepted at their value. The influence of the agent pressure, which is universally manifest in nature in one or more of its several forms (Appendix 1), was not until then considered a paramount factor in the existence and growth of the living substance.

Any consideration of the part pressure might play in the existence of Iife leads to a question of importance. How can such a part be studied to best advantage? The solution arises immediately: The animal embryo offers more possibilities than the adult, as the embryo is small; it develops gradually but quickly by differentiation; and it can be subjected to compression with ordinary apparatus. Obviously the independently de- 
veloping embryo is more adaptable than the inter-uterine fetur. Thewriter's decision to work with the eggs of the fowl was made in the fall of 1932 when it was his pleasure to hear that an English investigator (or group of workers) had recently subjected such eggs to compression with the result that embryonic development had been greatly accelerated. He attempted to secure the original account of the work; however, after fruitless search he decided to dispense with it and investigate the subject independently. It was obvious to him that such circumstances of acquaintance with antece-dent work did not admit of corroboration or disagreement. Therefore, the present writer formulated his method of procedure in such a manner that it would, first of all, serve as andequate basis for a study and determination of the general effect of compression. The possibility of subsequent specialized experimentation based upon subsequent findings was anticipated.

\section{II.}

\section{THE REVIEW OF IITERATURE}

A. Amhibian Eggs. Pflüger and his collaborators applied their apparatus to the segmenting eggs in such a way that hydrostatic pressure was created in the cytoplasm without change of any kind in the surrounding environment. It can be understood that such a pressure was not great because the maximum was that Which did not tax the tensile strength of the cell membrane to the point of rupture. Even so, the internal pressure invariably 


\section{$-4$}

caused the first cleavage plane to appear at right angles with the parallel plates of giass. This effect is not yet satisfactorily explained. Whether protoplasm is to be regarded as a semi-solid and subject to compression lines, or whether a true liquid with equal pressure in all directions is a question which may be of significance in explaining the pressure effect as determined in this problem. In fact, certain observations subsequently recorded, it is hoped, will throw some light on Pflüger's phenomenon.

B. Pressure Teratogeny. Perhaps the earliest account of the application of extra-cellular pressires to the embryo is that of Weldon (1902). His work included introducing water through the shell and membrane of larger end of the developing bird's egg by means of a siphon from a reservoir. In that manner not only was water lost by evaporation replaced, bat also a pressure was created. Although a definite morphologic change was not invariably produced, several cases of anamiotes resulted. Lillie (1903) attributes the production of such abnormalities to an hydrostatic pressure which so forced the embryo against the immovable shell. that the normal up-folding of the amnion was more or less prevented.

In the same paper (1903), Lillie describes several experiments which throw some light upon the mechanical factors of amnion development. By partially and completely destroying the lateral amiotic folds, he was able to materially retard the closure of the somatopleure to form the body wall. Upon that

evidence he assumed an interdependence between formation of 
amnion and body wall.

As to the occurrence of anamniotic specimens without the aid of man, Dareste (1879) claimed that he had observed several, one of which was living and normal in all respects excepting the complete absence of amnion. He attributed many cases of teratogenesis to an antecedent condition of partial anamiotic development. (Appendix 2).

C. Modification of Cardiac Tissue by pressure. That hycrostatic pressure produces definite physiological changes in the beating heart of certain animals is demonstrated in the work of Edwards and CattelI (1928). Their report can be sumarized as follows:

1. Moderately high pressures produce a marked increase in the amplitude of contraction of the frog and terrapin heart.

a. The initial cycle (as recorded by electro-cardiograph) after compression is greatly augmented.

b. The maximum effect is apparent after the third or fourth cycle.

c. The effect of pressure as manipulated by these workers is immediate although not instantaneous.

d. The increase in amplitude of contraction is not an enduring effect.

e. The normal cycle is gradually resumed upon release from compression.

2. Pressure has the effect of increased heart rhythm. a. The normal cycle of the frog's heart occurs every 3.9 seconds while at the time of maximum amplitude 
under pressure, it occurs every 3.6 seconds.

b. Upon release from compression, the cycle time of 4.2 seconds is assumed, whereupon the normal i-s gradually attained.

D. Pressure Modifications of Cleavage and Heart Rate in Marine Forms. Edwards and $D_{\text {raper }}$ (1932) have carried on further experimentation with cardiac modification in the Fundulus embryo. They conclude that hordrostatic pressure as high as 1900 pounds per square inch does not produce any evident changes in. cell constituents. In all test groups subjected to pressures from 1300 to 1900 pounds, however, a definite retardation of cell divisions was observed. A few abnormalities were produced; these were types showing gross body distortion, cardjovascular irregularities, and tendencies towards anopthalmas. Teratogenic specimens, however, were not numerous and there were no dominant anomalies.

The automaticity of the Fundulus heart is slowed and can even be completely inhibited by pressure. Upon release from compression the original speed of contraction returns within a few minutes.

That arrhythmia, local block, and isolated fibrillation are not a result of the direct action of compression on the Inhibitory nerve me dhanism is proved by Ewards and Draper by sectioning all nerves controlling heart action. 


\section{THE INVESTIGATION}

A. Object. The purpose of carrying on the series of experiments was two-fold. A determination of any change in embryonic development which micht be brought about by increasing the absolute pressure of the environment was necessary; and such an aim involves a detailed study of the developmental structure of the embryos of definite chronological ages, as well as investigation of possible abnormal growth, whether such growth is general or restricted to certain local organs by dysmorphic differentiation, had to be presumed. These probable results were outlined for convenience of later definition as follows:

1. Changes of either accelerating or retarding nature with or without material increase or decrease in body size.

2. Increase or decrease in body size without acceleration or retardation.

3. Possible teratogenesis accompanying either of the above conditions.

4. No alteration of form or size.

The second aim evolved itself from the expected findings as a consideration of the causal factors concerned with change. In all probability changes effected in the embryo by the action of an increased pressure environment would involve a modified physical and chemical relationship of cells and organs.

B. Apparatus. The very fact that pressures were dealt With in the se experiments necessitated the solution of a mechanical problem. After much experimentation with various contri- 
vances, the author hit upon an apparatus suitable for the requirements of the investigation.

A corpression cylincer was designed of solid brass three inch piping. One end was permanently sealed by screwing on and soldering in a thick head of the same metal, while the other was fitted with a trap cover which could be turned very tightly uoon a firm rubber washer. Through both the sealed cap and the removable cover a three-eighths inch brass pipe was sealed with litharge. A needle valve was attached to the opening at the cover; from this a rubber tubing led to a beaker of water for the purpose of quantitative determination of air circulation through the chamber. A third small brass pipe vas screwed into the side wall of the apparatus in such a way that a thermometer could be inserted and sealed by fitting with a short piece of high pressure tubing and two tubing clamps. To the inlet was clamped a four foot length of pressure tubing; which at its other end was attached to the compressed air cylinder and its reducing gauge.

By means of a system such as described above, a continuous flow of air under pressure as high as one hundred pouncs coufd be maintained for lons periods. Since the volume of the compression chamber was known ( 400 cubic centimeters), the speed of displacement could be computed at a.l times during incubation. This precaution was necessary to keep the carbon dioxide percentage below .01, which is the optimum described by Romanoff (1930).

An electric laboratory incubator of ordinary design was used in all test work, while a hot water Buckeye model of accurate 
adjustment served for controls. Each proved efficient in its special capacity; the one because it was easily regulated for long and continuous use, and the other because it was better fitted to maintain the adequate humidity level and could be operated independently of test work upon occasion.

A discrepancy of temperature was found inside the pressure chamber. This increase of five and one-half degrees Fahrenheit was at first not understood. Later however, itwas attributed to high conductivity of the metal used in construction, and possibly a greater conduction of compressed air.

c. Haterials. The egge used in these experiments were from a single flock of Rhode Island Reds owned by Senator Jessie H. Netcalf. Their fertility and hatchability was unusually high, as evidenced by excellent results in the Sacher Farm incubators. Each was graded as closely as possible for size, shape, shell formation, and freedom from blood spots and other visible imperfections. Weighing, however, was not resorted to as a means of securing uniformity, al though the usual grading process was performed by the hatchery operator. No eggs more than twenty-four hours in age were used, and the greater part of them were less than twelve.

The compressed air used was secured under a guarantee of purity and freedom from oil and toxic substances.

D. Method of procedure.

1. Uniformity of incubation. After the completion of several tests and experiments, the object of which was a 
determination of the most accurate method for designating the chronological age of the test embryos, it was decided that the tro eggs to be subjected to test conditions at one time should be sealed in the chamber before either the eggs or the chamber were heated. Upon connection with the rest of the sysem, the pressure unit was placed immediately into the pre-heated incubator.

A low compression was then admitted, after which the maximum of pressure was gradually but quickly increased within a half hour. Incubation time was recorded from the moment at which a temperature of $103^{\circ}$ Fahrenheit was attained. In every case this period was found to be just two hours after the unit had been placed into the incubator.

Such a procedure, the author believed, if followed diligentIy, was the most that could done to maintain accuracy and uniformity of timins. Never-the-less, the fact that the eggs of birds are fecundated in the oviduct and vary in the speed of their passage to the exterior leads to an unavoidable lack of uniformity in the development of freshly-laid eggs.

Equaliy exacting precautionary measures were carried out with the control specimens. Although the aim in this case was not primarily to incubate controls simultaneously with the tests, but rather, to produce embryos of as nearly as possible the chronological age of those developed within the pressure chamber. Imphasis was placed upon the representative development age; and to accomplish such an aim, a large number of eggs for eachage group studied was incubated under normal conditions. 
That specimen which uoon careful examination proved to be analogous to the mean of development of all the rest (any abnormalties excepted) was designated the control, whether or not it corresponded in all structural and evelopmental details with the comonly esignated chronological age.

2. Compression Methods. Without involving unnecessary detail the author lists briefly the various procedures he carried out in his preliminary handing of compression.

a. A two hour period of waming followed by gradual rise of compression over a period of five hours. b. The same preliminary warming followed by a comparatively quick, though gradual, increase of pressure during a period of thirty minutes. c.Gradual increase of pressure over five hours without a period of warming.

d. Quick compression simultaneous with heating. e. Normal incubation up to certain ages (24, 33, 48,60 , and 72 hours) outside of the compression chamber, followed by gradual and comparatively quick pressures.

f. Gradual compression before heating.

. Comparatively quick compression before heating. All of the above tests were made in an endeavor to determine a set of conditions which would be workable as well as optimum in the ensuing experiments. Since methods $d, f$, and $g$ proved to be of equal advantage from the standpoint of results, that of comparatively quick compression simultaneous with 
neating was adopted because of its convenience. However, the results of some of the other methods have a definite bearing on the problem; these will be dealt with specifically in the general results of this paper.

3. Histological Technique. For the purpose of uniformity, only two general methods were used in the preparation of embryos for study. The one was admirably adapted for preserving seventytwo hour and younger specimens. It comprised fixing in formolnitric (Appendix 3) with subsequent treatment in Worcester's fluid. After a rather light staining with alum cochinel (Appendix 4) the specimens were mounted entire. A painstaking and uniformly timed schedule was followed throughout, and the resulting beautifully stained and cleared preparations served their purpose well. Older embryo were fixed in Bouln's (modification 3), sectioned in paraffin, and stained with Delafield's haematoxylin and eosin. Counterstaining made possible a study of cytological as well as morohological structures.

E. Results. Several methods of observation were emoloyed with discrimination in a specific study of each stage and circumstances of variation of the embryos under consideration; viz, comarison of test and control specimens on a basis of observation of structure, and determination of gross- and micro-measurement; comparison of histological and cytological detail, where applicable; and comparison on a basis of relative change due to varying degrees of compression. Anatomical details will be given for the different age groups. 
Effects of Various Conditions of Incubation. Eggs normally incubated up to $24,33,48,60,72$, and 122 bours were dead in most cases when removed after periods of comoression at twenty-four or thirty pounds. The same result existed whether quick or relatively slow pressure was applied. In the forty-eight hour specimens and older specimens death was in most cases caused by hemorrhage. Extravasation of blood into the amniotic cavity through a rupture of the atrium was the predominant form, while in the 122 hour chick the bleeding occurred along the aorta. In almost eveycase death took placeimmediately upon the onslaught of pressure, for no specimen given such treatment advanced beyond its development at the time of compression. The application of various pressures after a period of warming longer than five hours always resulted sooner or later in death at an early age. No actual mounts could be made of such specimens because of dinintegration before removal. However observat ons pointed to death before the fourteenth hour.

Two eggs which had been incubatec normally for seventy-nine hours were subjected to thirty pounds of pressure applied very gradually (maximun not reached until the ninety-irst hour). One chick had died, while the other, although its appearance was at first that of death, proved to be in a condition of cardiac flbrillation. An arrythmical beating set in soon after renoval. $A_{s}$ an explanation, it is reasonable to assume that the chick "rould have soon died under continued compression. This case of fibrillation was not a result of lowerins the pressure; at least, no other occurrence of such cardiac modification came to 
the writer's notice in all subsequent work. At any rate it is very probably that fibrillation and heart block caused the death of the first embryo.

$$
\text { Twenty-five-and-one-half hour embryos. }
$$

Four newly laid eggs were subjected (during two experiments) to test conditions of thirty pounds of compression for trentyfive and one-half hours. Six more were incubated under normal conditions. Of these one was removed thinty winutes before the twenty-five-and-o-half hour period had been completed; two at the period, and one respectively at periods one, two and three hours later.

Body form. Although one egig was sterile, the remaining three test specimens presented the appearance of normal embryos. All three had formed definite head folds. Two fully formed somtes were present in each, and in none was the third somite comleted. AlI three were more advanced than either of the two twenty-five-and-one-half hour controls. In fact, the only control specimens which showed more development were those removed at twenty-seven-and-one-half and twenty-eight-and-one-half hours. The twenty-seven-and-one-half hour control was almost identical With the test specimens, excepting a very slight increase in development of the third somite. (See Plate 1, Figures Iand 2.) Body size, Careful measurements of all test and control specimens showed that pressure brought about a slight diminution in size.

Forty-seven-hour Embryos subjected to thirty pounds of 
pressure (plates 3 and 4 ).

Body form. Considerable variation was apparent in these

embryos. AII six of the test specimens showed flexure and torsion of a more advanced stage than any of the controls. In most cases the 10oping of the test hearts was more pronounced than in the control embryos. To form of gross abnormality appeared in these embryos.

Extra-embryonic structures. The extra embryonic splanchnopleures of the test specimens were eomewhat amaller in diameter than those of the controls; and blood islands were not in the same advancement of coalescence.

Sixty-six-and-one-half hour embryos subjected to thirtyfive pounds of pressure. (Plates 5 and 6).

Body form. The only appreciable difference between three test specimens and control embryos is a slight advancement of the tail fold of the amion and an accompanying more advanced rotation of the caudal portion. (See Plates 4 and 5).

seventy-two hour embryos subjected to sixty pounds of pressure.

Body form. Four embryos were removed at this stage. These show more abnormality than any other group. Plates 6 and 7 , show the two types of teratogeny encountered. Plate $I$ is a camera lucida drawing of that one of the group showing most variation, while plate 2 is typical of the other three.

All specimens are somewhat advanced in anatomical structure. For example, an average of about thirty-nine somites compares with normal embryos older than eighty-three hours. Anterior 
and posterior Iimb-buds show advancement un to eighty hours. Notwithstanding such structural advancement, the se chicks are only about one half the length of normal ones. This condition of diminution and emaciation is partly accounted for by an excessive thoracic flexure. A lack of cephalic flexure, however, leads one to attribute the extreme smaliness of these embryos to the direct effect of pressure.

Heart structures in these embryos are extremely large and well developed. In fact, when camera lucida drawings are super-imposed upon those of nornal seventy-two hours hearts, they are larger. Thickness of heart wall is in all cases nearly tiice that of controls.

When these embryos were first removed it was noticed that the extra embryonic structures were very poorly developed and very small. The peripheral third of the vascular network was found to be atrophied to the extent that circulation was very much hindered. Such a condition may explain a very pronounced arrythmia which was observed in the embryo pictured in Plate 7. Two specimens were without anterior amniotic structures of more than rudimentary formation. Ninety-six-hour embryos subjected to fifty pounds of pressure.

Body form. Only two specimens of this group were removed. One was somewhat smaller than the typical ninety six hour control. In structural development it was advanced. The other specimen was dead at the eighty-fifth hour stage and showed 
nemorrhage through a rupture of the left auricle. The extraemoryonic circulatory systems of both were somewhat poorly developed. Gross abnormalities of flexure and torsion were consumated in an contra-flexion in the cervical region of the living specimen. Histological observations did not reveal other malformations.

General results of subjection to pressure higher than sixty pounds.

All attempts to produce living embryos under these conditions failed. Sixty-five, eighty, and one hundred pounds invariably caused death at an early age. It is of interest however, that death occurred earlier when compression was high than when sixty-five pounds were used. With one hundred pounds death occurred at the thirty-three hour stage; with eighty, at the thirty-eighth (Plate 8); and with sixty-five, at the forty-second or forty-fourth. 


\section{SOUSSION}

In the agent pressure we have an instrument of two-fold affect on the growth of the chick embryo. Almost invariably in these experiments, a decrease in size has been accompanied by an accleration of structural development. This fact might be considered paradoxical in view of some of the results of earlier observations. Draper and Edwards (1932) show that relatively high pressures retarded cell division in the early cleavage of Fundulus. It is reasonable to consider that mitosis might have been likewise inhibited by a change in viscosity or ionic disturbance in the chick protoplasm. However, such a change, although it might account for the general diminution of body size in embryo chicks, could not be responsible for the present acelexation which indicates that cleavage and cell division have proceeded at a faster rate than normally; however, it may be that differentiation has proceeded at an increased rate without an accompanying increase in rate of cell proliferation. It is also possible that relatively low pressures produce a lowering of viscosity, especially where heat is a factor, instead of an increase. There is no specific evidence at hand in support of this view. However the author hopes to carry on experiments in the future in order that he may reach some conclusion.

The almost complete absence of the formation of the anterior portion of the amnion in two of the seventy-two-hour embryos subjected to sixty pounds of pressure substantiated the observations of Teldon (1902). 
anion folds was mechanically inhibited by contact with the she11. The statement of $D_{a}$ reste (Appendix 2) applies adequately in this case, for both specimens show greater degree of monstrosity than any of those in which amion formation ha.s not been prevented.

The fact that embryos subjected to low pressures show a relatively small developmental acceleration leads to a comparison with the large amount of acceleration with higher pressures. In fact, there is sufficient evidence to believe that acceleration is proportional to increase in pressure.

In contrast to the above, it is also true that the stunting effect is proportional to the amount of pressure. This conclusion is based upon the fact that all embryos subjected to thirty pounds, including the sixty-six-and-one-half-hour specimen, were far nearer the normal size than were those incubated. under fifty and sixty pounds.

111 of these considerations come to an end with the application of more than sixty pounds of pressure, for death resulted at an early age in each case of such application. Upon this evidence the author assumes a lethal pressure somewhere above sixty pounds, although an exact lethal point has not yet been satisfactorily deternined. No evidence of early malformation as a fore-runner of death due to a lethal pressure has yet been observed, for none of the young embryos subjected to that pressure showed gross malformations. The writer would be more prone to assume that death was caused by a lack of oxygen somehow brought about by a change in gas tension. At any rate, 
the lethal factor operates in proportion to pressure applied, for death occurred earlier when pressure was increased. 


\section{CONCLUSIONS}

The fact that an increased pressure accelerates the morphological development of the embryo chick on the one hand and retards normal growth in size on the other cannot be explained on a basis of viscosity change of protoplasm.

There is a possibility that protoplasm may become less viscous when subjected to both pressure and heat.

A lethal pressure exists. Fowl embryos developed in a pressure just below it show a high degree of gross malformation. 


\section{SUMNARY}

pressures up to sixty pounds cause an acceleration of structural development in the embryo chick.

This acceleration is proportional to the degree of compression.

Such acceleration is accompanied by a marked decrease in normal development of size.

Teratogenesis is brought about by pressures near the lethal point. The predominant forms of malformation are: abnormal flexure and torsion, large hearts with greatly thickened walls, failure of formation of the anterior fold of the amnion, and atrophy of the extra-embryonic c1rculatory system.

A pressure of sixty pounds is sufficient to prevent the rise of the anterior fold of the amnion. Stunting is proportional to the degree of compressions. A lethal pressure exists somewhat above sixty pounds. 


\section{VII}

\section{ACKNOWLEDGEMENTS}

The author wishes to express his sincere appreciation to several persons who gave him advice and services indispensable to the undertaking and completion of this investigation:

To Dr. John Barlow especially

To Prof. H. O. Stuart

To Dr. Harold W. Browning

To C. Lester Coggins

To Dr. A. A. Vernon

To Prof.J.W. Ince

To Prof. H. M. Emery

To Dr. W. G. Parks

And to Mr. J. F. Archibald 
VIII

APPENDIX

I. Pressure as designated in these experiments is in reality a hydrostatic force because the avian egg is enclosed in a thickness of semi-liquid albumin. The air compression utilized completely surrounds the porous shell and is contacted with the albumin and other egg constituents in the form of hydrostatic pressure.

II. Dareste (1897) "J'ai signale, depuis longtemps, l'arret de development de l'amios et les anomalies nombreuses que cet arret partiel determine chez l'embryon. C'est la cause la plus frequente des monstrouosites simples.

III. The fomol-nitric fluid used for fixing young embryos in this investigation was made according to the following formula:

$40 \%$ formaldehyde -----5 parts

Water -

Nitric acid (807) -.- 5 parts.

IV. It was found that alum cochineal diluted with one third of its volume of distilled water stained more selectively than a heavier stain followed by acid treatment. 
IX

\section{BIBLIOGRAPHY}

Adamstone, F. B. 1931. Journ. Morph. and Physiol. 52: 47. Bogojawlensky, A. and G. Tammaun 1898. Ze1tschr, f. phys. chem. $27: 457$.

Bridgman, P.W. 1914. Journ. Biol. Chem. 19: 511.

Dareste, C. 1879. Paris.

Draper, J.W. and D. J. Edwards. 1932. Biol. Bull. LXI11(1): 99. Edvards, D. J. and MeKeen Cattell 1928. Am. Journ. Physiol.

84: 472 .

Heilbrunn, L. V. 1927. Quart. Rev. Biol.

Lille, F. R. 1903. Biol. Bull.

Lillie, F. R. 1927. The Development of the Chick. Henry Holt and Co.

Norgan, T. H. 1927. Experimental Embryology. Columbia University Press.

Pfluger, E. 1884. Arch. Ges. Physiol. XXXIV.

Romanoff, A. L. 1930. Journ. Morph. 50: 517.

Weldon. 1902. Biometrika. Vol. I Part III.

Nerber, E. I. 1916. Journ. Exper. Zool. 
All illustrations are camera-lucida drawings to scale $(27 X)$.

Below is 27 X 1 M. M. which can be used in comparing the various figures.

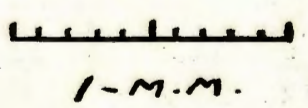




\section{PLATE I.}

Figures 1 and 2, respectively, are typical of several test and control specimens subjected to 30 pounds of pressure. Figure one shows a 25롤 hour embryo which is very nearly comparable to the $27 \frac{1}{2}$ hour specimen, (Fig. 2) in structural advancement. It is somewhat smaller, however, than the control. 


\section{PIATE I}

Fig. I

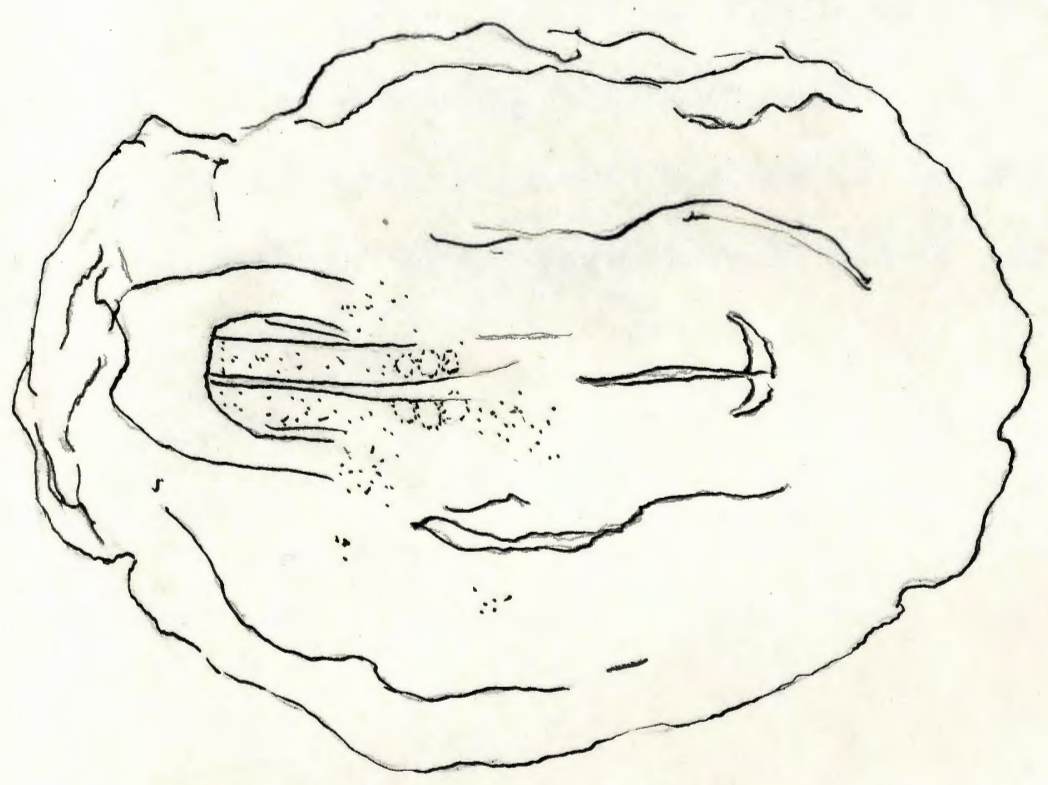

Fig. 2

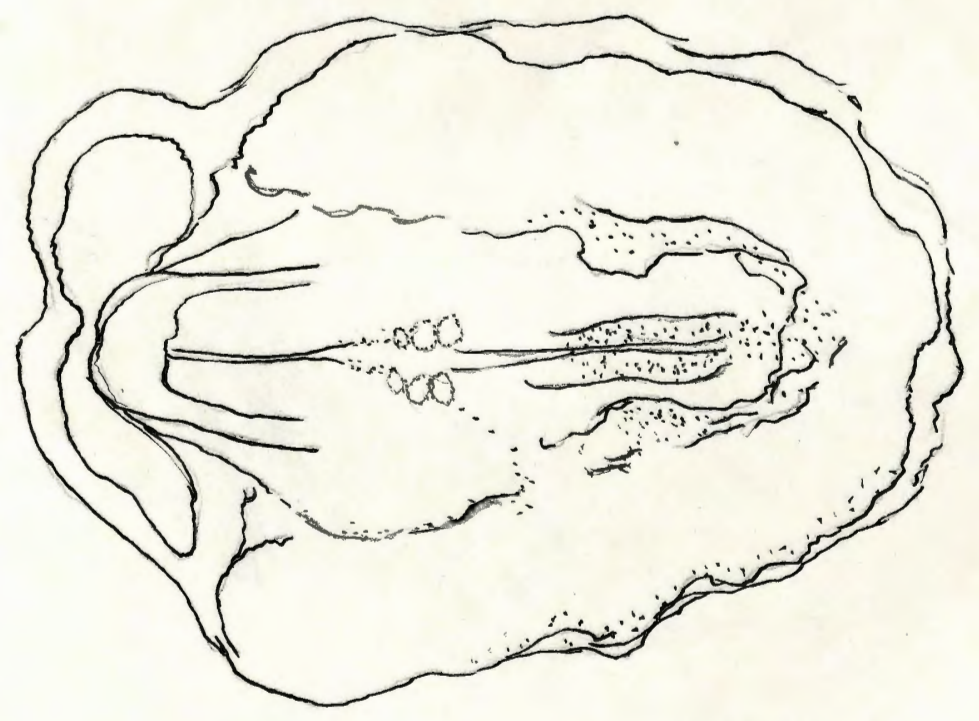


PLATES 2 AND 3

Figures 1 and 2 of Plate 3 are camera lucida drawings of typleal test 47 hour specimens. They differ from the control (Plate 4) in that they show more advanced flexure and torsion, and more pronounced heart loopings. As can be determined by measuring according to the accompanying scale, the tests are smaller than the control. 
PLATE 2

Fig. 1

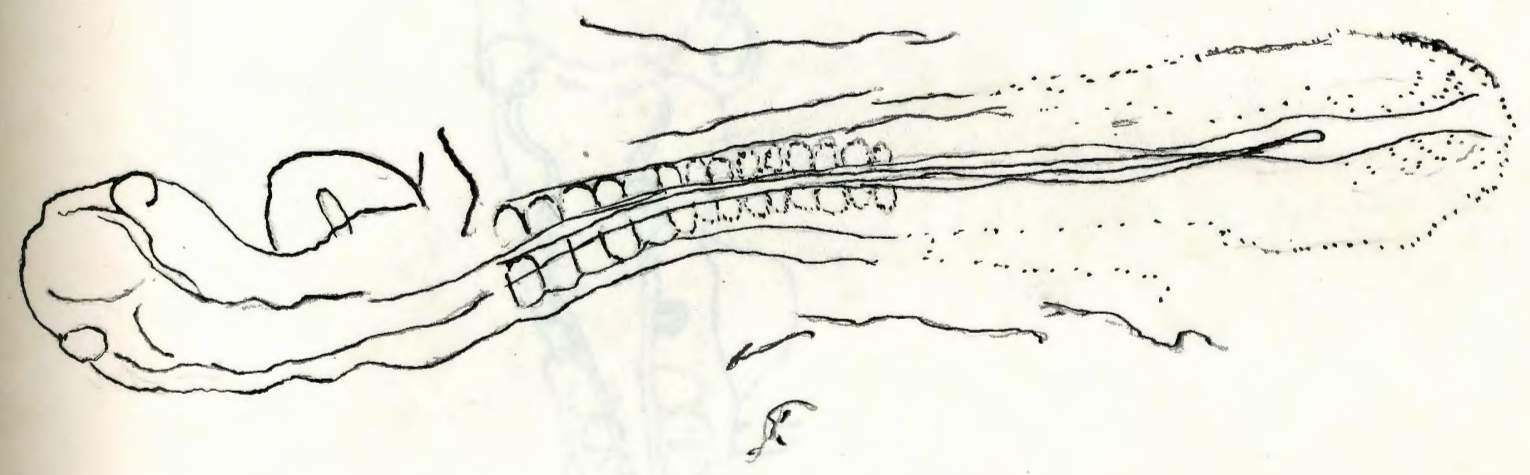

Fig. 2

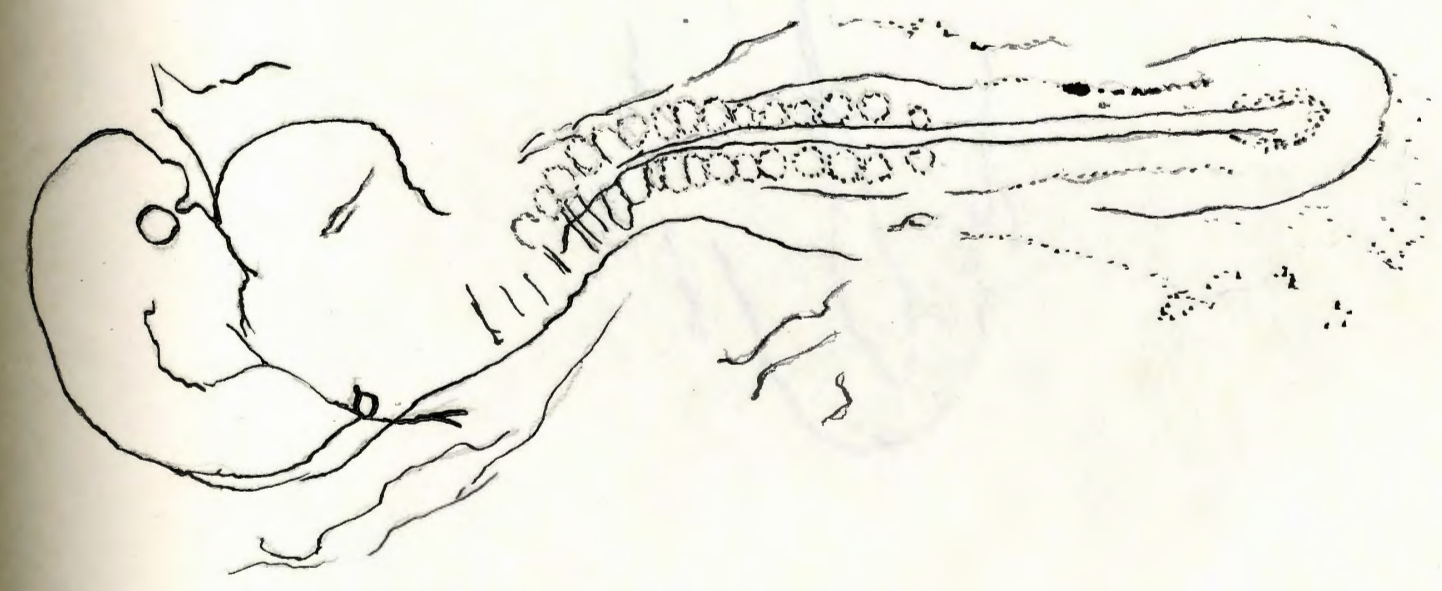


PLATE 3

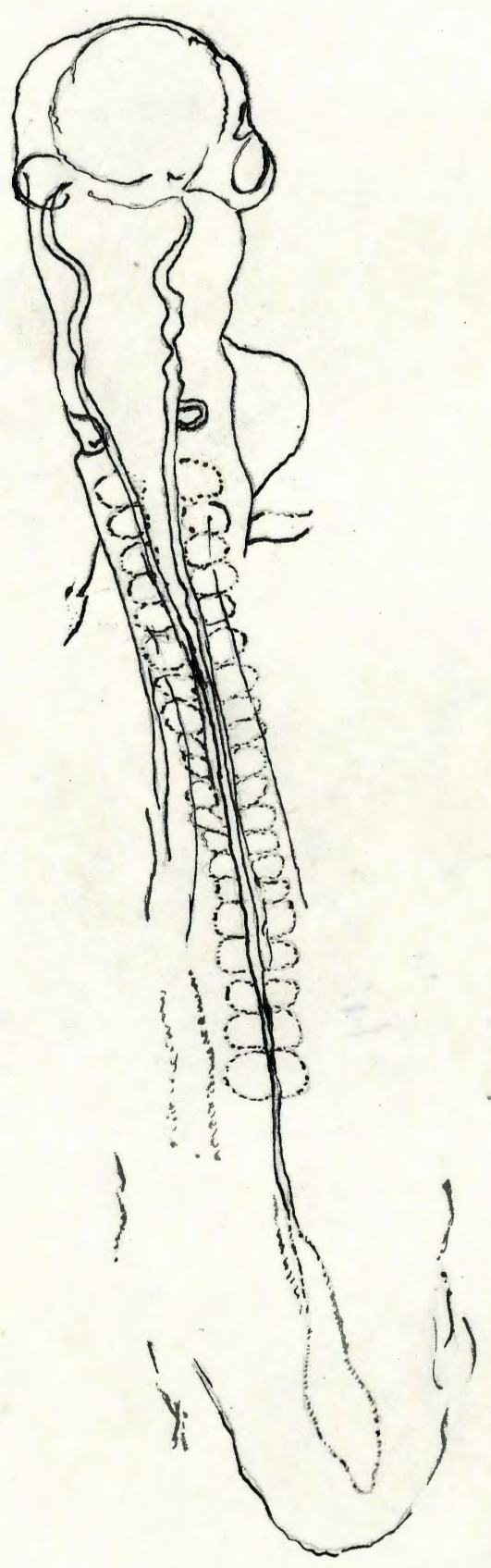




\section{PLATE 4}

Plate 4 is typical of $66 \frac{1}{2}$ hour embryos subjected to 35 pounds of pressure. The only appreciable difference and the control (Plate 5) is a slight advancement of tail fold of amnion and caudal rotation. 
PLATE 4

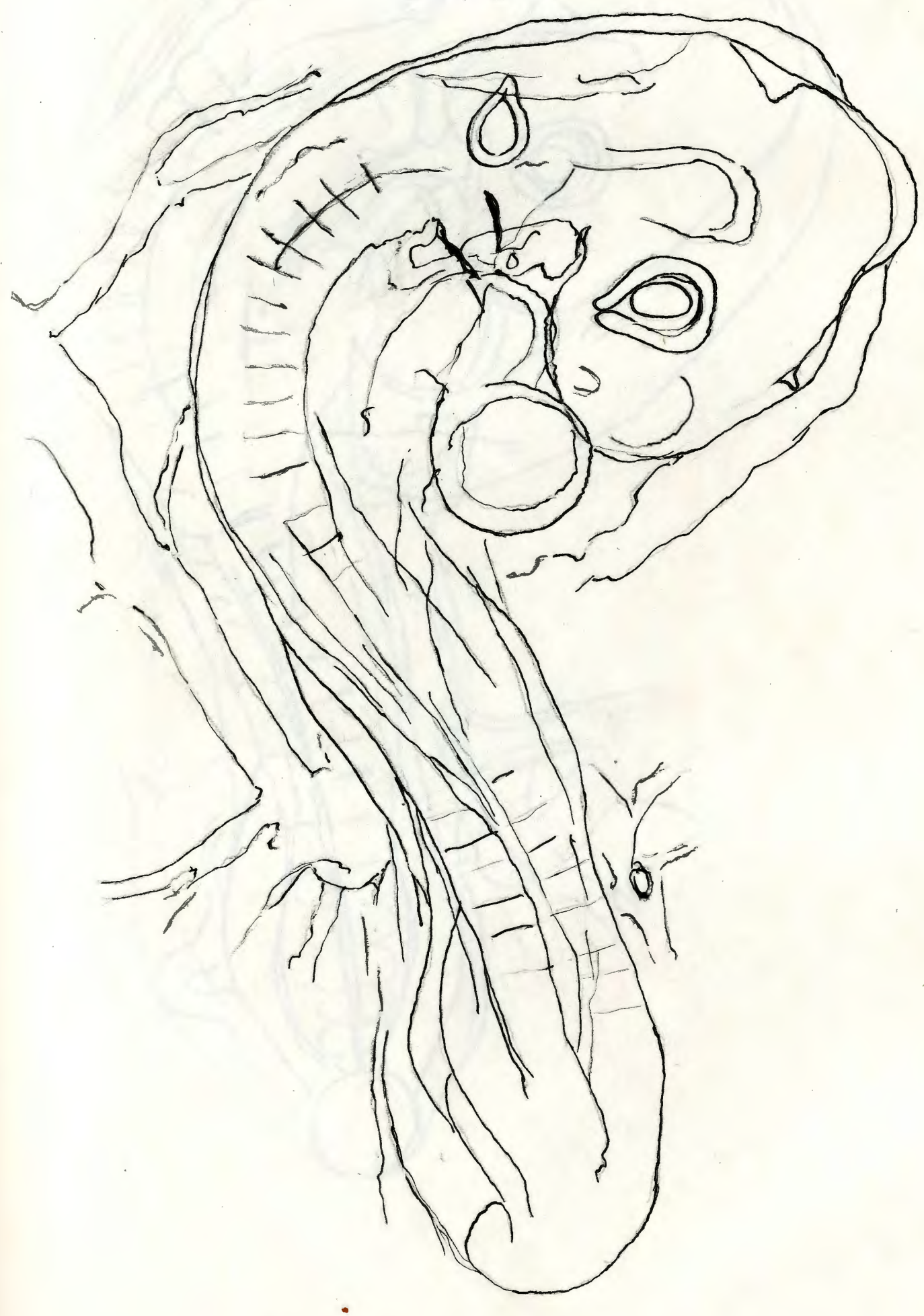




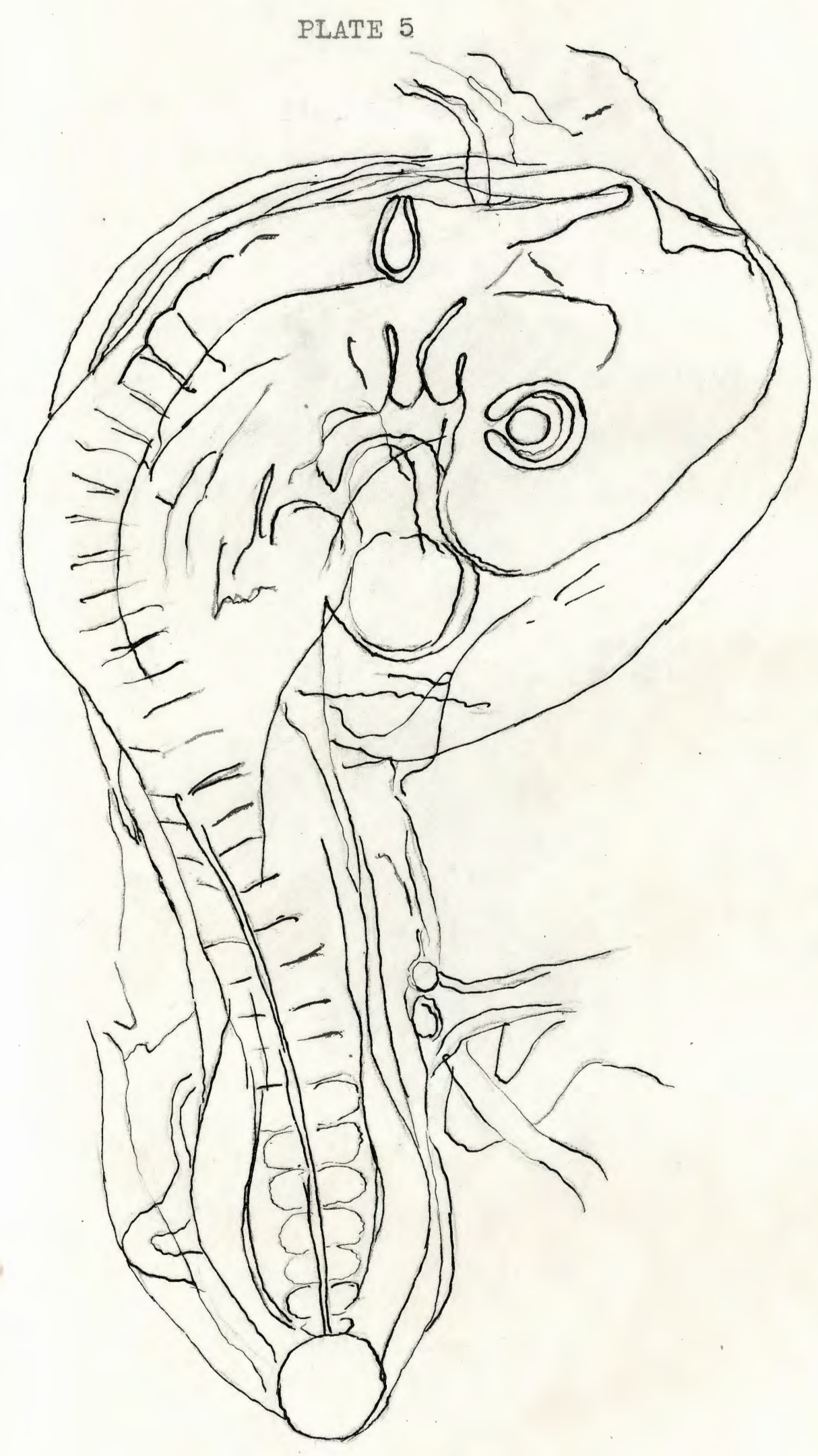




\section{PLATES 6 AND 7}

Sixty pounds of pressure seems to be near the lethel pressure as evidenced by the terato-logical effects shown in Plates 6 and 7 . Plate 6 shows a single specimen of extreme abnomality, whereas, Plate 7 is typical of the other embryos subjected to the near lethaypressure. Note the extreme diminution of these embryos as compared the advanced anatomical development. Extra-embryonic structures were poorly developed. The peripheral third of the vascular network was so much atrophied that circulation was hindered. 
PLATE 6

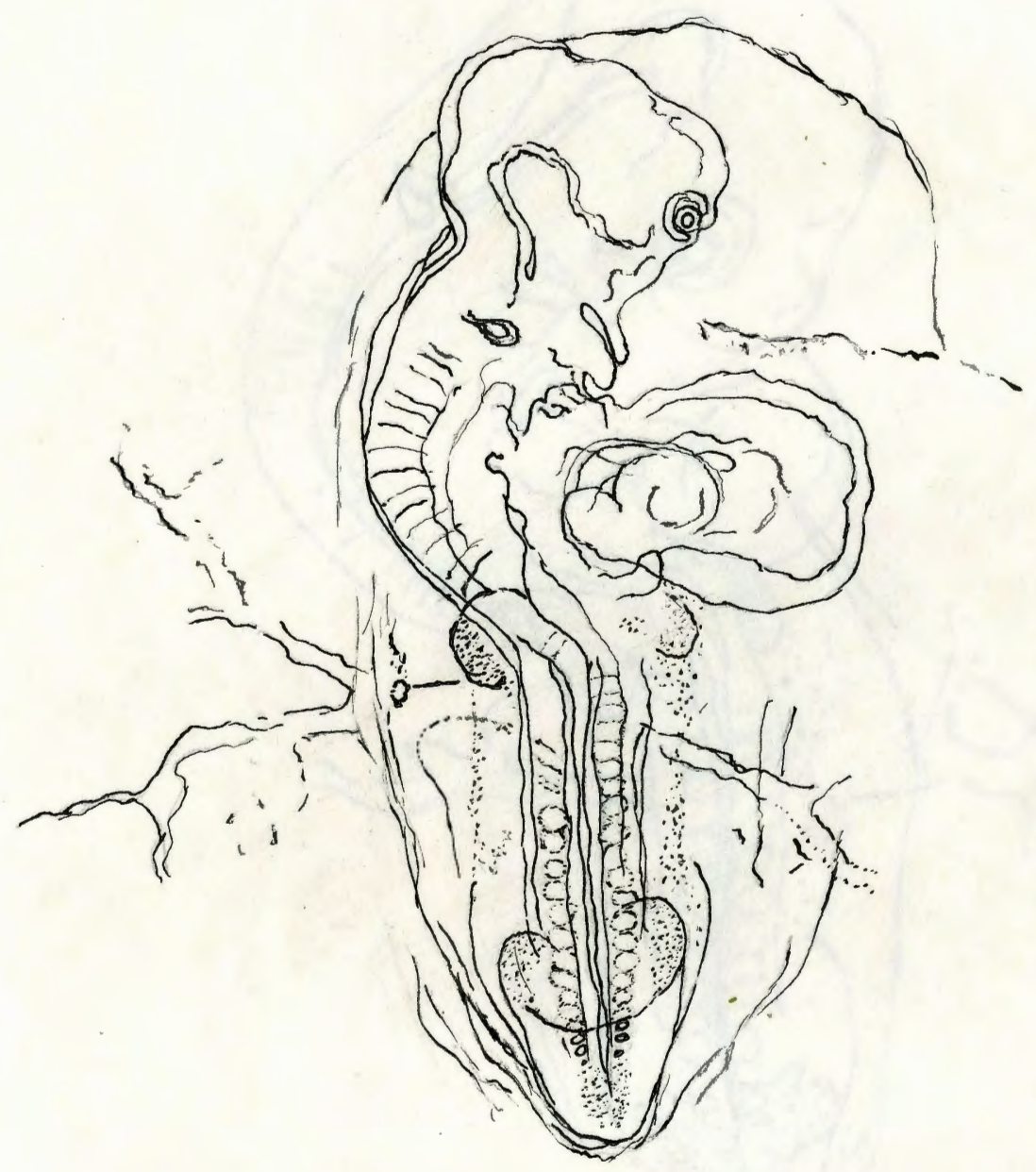




\section{PLATE 7}

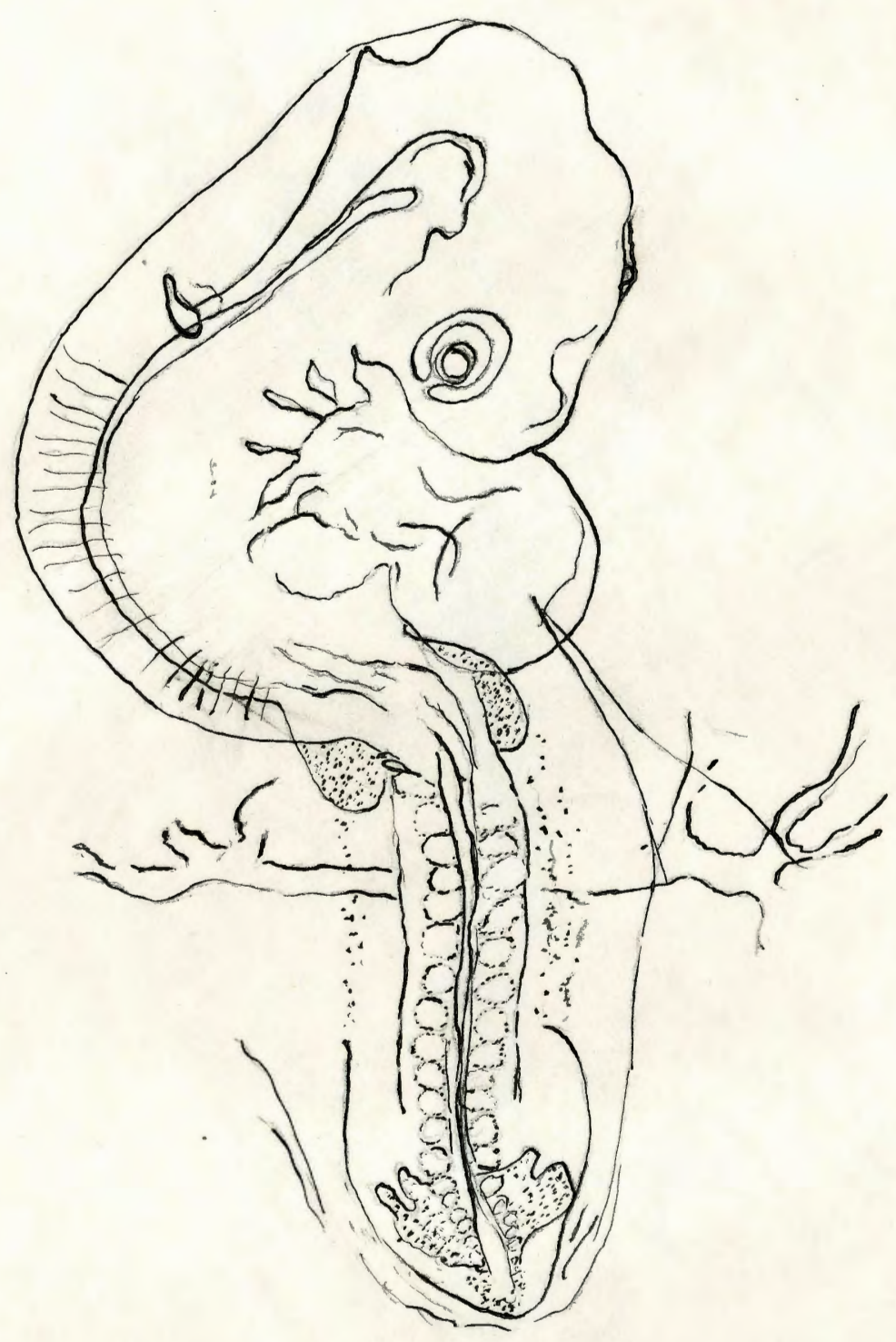


PLATE 8

This embryo was dead when removed. With 80 pounds of pressure advancement did not proceed beyond the 22 somite stage. (see p. 18.) 
PLATE 8

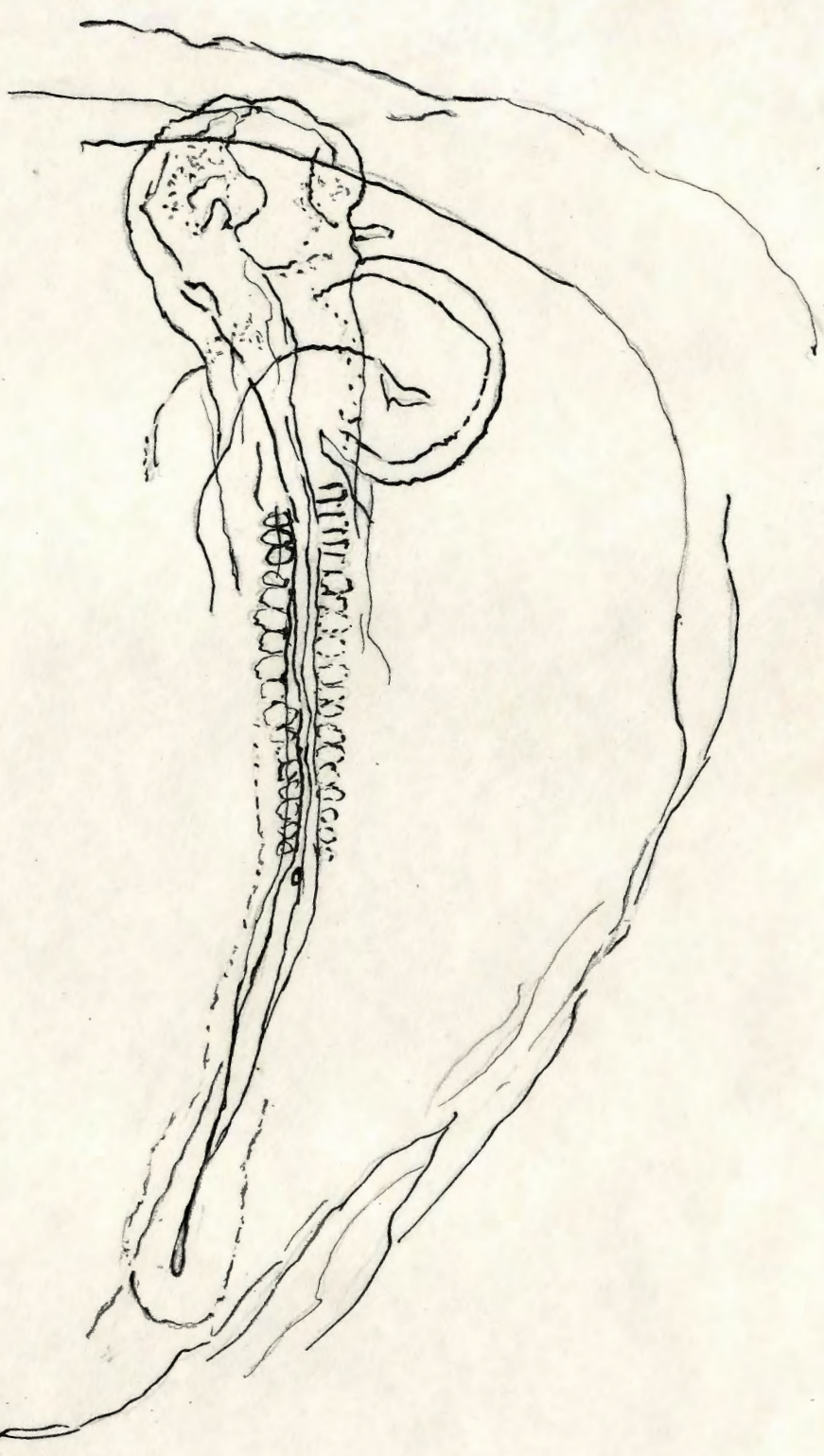

